\title{
Information Literacy Instruction and Assessment in an Honors College Science Fundamentals Course
}

\section{Corey M. Johnson, Carol M. Anelli, Betty J. Galbraith, and Kimberly A. Green}

The Washington State University Honors College course, UH 290, "Science as a Way of Knowing," engages freshmen in scientific inquiry and scholarly literature research. The UH 290 instructor, a learning design consultant, and two librarians collaborated to develop and deliver the course's information literacy curriculum. The team used student surveys, research blogs, case studies, library instruction sessions, homework problem sets and exams. Students gained from scaffolded instruction including hands-on practice activities and feedback; embedded assessments informed adjustments to the course syllabus and activities. This case study details the progressively improved use of this approach and these tools over two semesters.

\section{Background}

\section{Information Literacy at Washington State University and Its Honors College}

In 2005, the Washington State University (WSU) Faculty Senate endorsed the "Six Learning Goals of the Baccalaureate," which were developed by the President's Teaching Academy. These goals (critical and creative thinking, quantitative and symbolic reasoning, information literacy, communication, self in society, specialty knowledge) were envisioned as a means to (1) articulate educational learning goals for all undergraduates irrespective of major; (2) serve as a framework for course and curricular design; and (3) help faculty and administrators align course and curricular goals for assessment and accreditation. ${ }^{1}$

The WSU Honors College adopted WSU's "Six Learning Goals," distributing them on bookmarks in student-friendly language and providing faculty workshops to help students achieve the goals. Serendipitously, endorsement of the goals coincided with a complete overhaul of the Honors College curriculum, which satisfies general distribution requirements of the university. In the new curriculum, all 200-level courses emphasize information literacy (including research in the primary literature), critical thinking, and

Corey M. Johnson is Head, Library Instruction, in the Holland Library at Washington State University; e-mail: coreyj@wsu.edu. Carol M. Anelli is Professor of Entomology in Food Nutrition Library at Washington State University; e-mail: carol_anelli@wsu.edu. Betty J. Galbraith is Science Librarian and Instruction Coordinator in Owen Library at Washington State University; e-mail: bettyg@wsu.edu. Kimberly A. Green is Director, Office of Assessment of Teaching and Learning at Washington State University; e-mail: kimberly_green@ wsu.edu. (C) Corey M. Johnson, Carol M. Anelli, Betty J. Galbraith, and Kimberly A. Green 
"ways of knowing" in the social sciences, arts and humanities, or sciences; student acquisition of these skills is prioritized over course content, which varies among instructors. This last point is important as teaching faculty often prioritize subject coverage above skill-based goals (such as enhancement of information-seeking abilities). ${ }^{2}$ By formal agreement, all Honors English Composition (Engl 298) sections have at least one library instruction session. Many other 200-level honors courses include library instruction; this is often the case for UH 290 depending on the instructor.

\section{Information Literacy at Research Universities: Library Involvement}

Like WSU, many research universities across the nation have taken steps to embed information literacy into their overarching goals and curriculum. Current roles for librarians in these processes vary greatly. It is clear that university stakeholders are increasingly deemphasizing traditional library quality measures (such as volume counts or number of books checked out) and instead want to know what students are able to do as a result of their interaction with library services and resources. ${ }^{3}$ While this mindset bodes well for robust librarian involvement in student information literacy skill building, there are still barriers to full participation. For example, at big institutions where departmental autonomy is often paramount, opportunities for developing anything beyond the traditional "one-shot" library session are uncommon. ${ }^{4}$ Also, university administrators often disagree about whether faculty or librarians should teach information literacy and do not regularly recognize and reward faculty/librarian collaborative information literacy projects. ${ }^{5}$ Some higher education accreditation agencies view libraries primarily as resource providers and minimize their role concerning information literacy instruction. ${ }^{6}$ Finally, within the arena of honors undergraduate education, many instructors falsely assume that these motivated students already possess the skills needed to identify and locate scholarly resources. ${ }^{7}$

One task is for librarians to gain quality opportunities to teach information literacy; it is additionally critical to assess information literacy skill development. In other words, librarians assume they contribute to student learning and, in many instances, have created outcomes and are doing more teaching; now they need to assess the impact of this work. ${ }^{8}$ In 2008, a survey of Louisiana schools showed that, while information literacy had more formal definitions across the respondent institutions, only half the institutions identified any type of assessment. ${ }^{9}$ The UH 290 information literacy instruction described in this paper features course planning, teaching, and assessment.

\section{Assessment of Information Literacy}

There are many dimensions to successful assessment. The American Association for Higher Education and Accreditation (AAHEA) has created a set of best practices for assessment. They posit that assessment is most effective when it "reflects an understanding of learning as multidimensional, integrated and revealed in performance over time." ${ }^{10}$ Learning entails not only what students know but what they can do with what they know. For UH 290, the authors devised an array of ongoing assessment techniques including online threaded discussions, culminating assignments, and group exams that challenged students to apply concepts learned to new contexts. Another key to effective assessment is involving representatives from across the educational community. "Faculty play an important role, but assessment's questions can't be fully addressed without participation by student affairs educators, librarians, administrators and students." ${ }^{11}$ The UH 290 team included active participation and contributions from a subject expert (professor and instructor of record), an assessment specialist from the university's center for teaching excellence, and two instruction librarians. 
Traditionally, a central facet of most assessment efforts is the student exam, but the higher education literature concerning testing continues to evolve. Educators and other learning experts are increasingly thinking that fixed choice tests are limited in their accurate measurement of student learning, because, for example, they impose unrealistic time constraints and do not test higher-level thinking skills. ${ }^{12}$ More generally, tests typically create artificial situations that do not judge how the learner would react in a real-world situation. ${ }^{13}$ Performance-based tests are preferable, as they simulate instances where students would appropriately use new skills and knowledge. ${ }^{14}$ UH 290 includes small-group take-home exams (3-4 students/group) and several case studies that demand critical thinking and performance to address authentic problems. Small-group activities allow students to discuss and potentially deepen their thinking; when this process is captured online (or by other means), instructors can see the students' strategies and successes as well as conceptual blocks and/ or misperceptions. This information can in turn guide instructional improvement. Loanne Snavely and Carol Wright have successfully used research portfolios with honors students to both "track the [research] process as well as individual progress." 15

\section{Information Literacy Instruction, Examples in Honors and Biology}

Despite a general scarcity in the library literature about information literacy instruction to honors students, there are several projects of note. ${ }^{16}$ In the early 1990s, librarians Abigail Loomis and Patricia Herrling collaborated with biology professors in the development and execution of an honors course focusing on evolution, ecology, and genetics. The librarians were pleased their efforts constituted what they described as "course integrated instruction." The biology professors and librarians worked jointly to design the information literacy teaching sessions and the student work accompanying the lessons. The student deliverables were assessed by both the teaching faculty and the librarians, and credit was assigned to the work. ${ }^{17}$ This model closely parallels the information literacy components of UH 290.

While Loomis and Herrling were largely satisfied with their collaborative project, they outline many factors that inhibited success. One central problem was the abbreviated time the professors allotted for information literacy activities. As the syllabus was developed, information literacy became marginalized; the library modules were pushed from the main lecture days to discussion recitations led by teaching assistants. ${ }^{18}$ The faculty essentially felt that subject coverage was paramount to the development of information-seeking skills within the discipline. ${ }^{19}$ As discussed later, in UH 290 the instructor initially did not provide sufficient class time for the librarians to thoroughly teach information literacy skills, a problem that was quickly rectified.

Loomis and Herrling also found some biology professors averse to the idea of teaching the process of information seeking, reasoning that they did not have formal training and that information literacy skills are proficiencies one "picks up here and there." ${ }^{20}$ Ironically, the same professors who classified information literacy skills as relatively intuitive also expressed concern about the potentially high level of difficulty embodied in the librarian-generated assessment pieces. More specifically, many professors felt the use of scientific reference materials and scholarly journal articles would overwhelm students. ${ }^{21}$ Unfortunately, because the librarians created class assignments under the influence of these professors' ideas, honors students judged the assignments as too simplistic.22 These problems were averted in the case of $\mathrm{UH}$ 290 , as the professor viewed information literacy skill-building as a critical course goal along with the adept use of library resources for scholarly research. 
In addition to Loomis and Herrling, Elizabeth Kraemer wrote about her experiences developing information literacy instruction for honors students (Oakland University). Kraemer draws a number of conclusions about honors students' responses to information literacy. They place high demands on themselves in terms of academic performance, yet are similar to other students in their tendency to experience "library anxiety" and be illinformed about information techniques and strategies. ${ }^{23}$ Regarding pedagogy for honors students, Kraemer recommends small group work, "advanced reference book usage," time for class discussion, and problem-solving work. ${ }^{24}$ All of these activities were used in UH 290. Kraemer provided library instruction as part of her Honors College Introduction to the Thesis course. During the first semester of group work, students had two class sessions with librarians; this was determined to be too few and thus was expanded to four sessions. This change helped the librarian become better acquainted with the students, and more of them sought research consultations from the librarians in the second semester..$^{25}$ In the case of UH 290, the authors learned from experience that one session was insufficient to thoroughly teach information literacy skills.

Librarian Ignacio Ferrer-Vincent and biology professor Christy Carello collaborated on a biology laboratory course, devising an overarching plan that included specific learning outcomes and assessment activities. ${ }^{26}$ Library instruction included the following conceptual areas: scholarly vs. popular sources, primary vs. secondary sources, selection of appropriate databases, procurement of scholarly articles and identification of articles as peer reviewed. Teaching strategies consisted of pretask instruction, a ten-minute group presentation based on a research assignment, and assessment via an end-of-semester survey. ${ }^{27}$ Each element of this overarching plan was also part of the UH 290 course.

In the end-of-semester feedback, Ferrer-Vincent and Carello's students self-reported an increase in their use of subject-specific databases for scholarly information. ${ }^{28}$ However, student difficulties persisted in two areas: (1) procuring articles through the library catalog; and (2) successfully locating peer-reviewed articles..$^{29}$ As discussed below, the authors' experiences with UH 290 mirror the successes and lingering problems described by Ferrer-Vincent and Carello.

\section{UH 290 Collaborative Design: Pilot and Redesign}

\section{First Semester: Classroom Activities, Surveys, Assignments}

To address its information literacy learning outcome, UH 290 was designed to include instruction by librarians and a series of activities requiring students to identify their information need and to search and evaluate scholarly sources. The course also included several assessment activities to identify students' achievement, their process and perceptions, and any bottlenecks hindering this outcome.

During the first semester of collaboration, the instructor presented several lectures on using scientific primary research articles. To augment the lectures, students read Gillen, ${ }^{30}$ which targets scientific information literacy skills, and Moran, ${ }^{31}$ which served as a model for homework assignments. The instructor asked the librarians to use one 50-minute session to cover how to select science databases and how to search for and procure scholarly sources. The instructor additionally requested that the librarians also address: parts of a scientific article, popular vs. scholarly sources, primary vs. secondary sources, and criteria for evaluating sources. The librarians prepared a lesson that included a series of short lecture segments about each topic.

As a direct measure of the effectiveness of the instruction session (and the instructor's lectures and homework assignments), students were asked to complete a take-home group midterm exam with questions based on the aforementioned 
library research skills (see Appendix A). In general, students performed poorly: 40 percent of student teams (groups of 4 students) could not locate scholarly articles using library resources; comments in their online threaded discussions revealed that students were frequently searching Google because they did not know how to locate resources through the library. The students' exam performance was disappointing not only because it came directly after a library instruction session but also because, on a precourse self-assessment survey, 50 percent of the students had reported being "comfortable conducting a literature search." The high selfassessment of honors students can mask their real skill level and pose challenges to library instruction if it is perceived to be unnecessary or even remedial.

Assessment activities also showed that students had difficulty classifying the articles they found. On the precourse self-assessment, students were asked to respond to this open-ended prompt: "In your own words, define a primary research article and explain its purpose in the scientific world." They did so with a high rate of success; eight of the fourteen students provided quality explanations, four had some correct elements, and only two were wholly incorrect. Thus, the vast majority at least provided the basic idea that a primary research article conveys results of the author's empirical research. Yet, while students could supply definitions, they were not nearly as successful applying that knowledge. One homework assignment asked students to select an article from the bibliography of the Moran article. Only ten of the fifteen students correctly identified their article as primary or secondary; all five errors resulted from incorrectly naming primary sources as secondary sources. Upon discussion with the students, the instructor/ librarians learned that the presence of a literature review in the article revealed a core misunderstanding; the students thought the article must be secondary because a literature review is an analysis of research in which the author(s) of the article did not engage.

In light of student difficulties locating and classifying scholarly resources, the instructor and librarians modified the syllabus, adding two additional instructional sessions. During these teaching lessons, the librarians took the time to demonstrate how to find scholarly articles from the item's citation and showed examples of primary and secondary articles in the field of evolutionary biology: in effect, modeling these key information literacy skills. Students' responses on subsequent assignments and exams showed marked improvement (discussed below). On the postcourse survey, 82 percent of students reported that they could retrieve electronic resources through the library. This represents a substantial increase $(31 \%)$ over the precourse self-assessment of this skill.

The precourse survey included two other questions related to information literacy: (1) explain how scientists communicate findings with their peers; and (2) explain the differences among primary research articles, research review articles, and research articles in Scientific American. Concerning how scientists communicate findings, 93 percent of the students' precourse answers were on target. As one might imagine, the postcourse answers were correct as well, but this time they included relevant vocabulary terms/ phrases such as "peer-reviewed" and "primary research article." Regarding the second question and the definition of a "research review article," about onethird of the students had initially falsely stated that a review article was a critical outside examination of one other study/ primary article, instead of a synthesis of multiple articles in the same research field or subfield.

\section{First Semester: Exams}

During the first collaborative semester, student performance on group take-home exams (see Appendix A) demonstrated some successful applications of target 
information literacy skills. The first exam challenged students to locate an original, peer-reviewed article that had been the focus of a news wire story. The students were then asked 10 subquestions (parts A-J), several of which required information literacy. Part A asked the students whether the article was a peer-reviewed publication and what evidence would allow them to answer with "absolute certainty." All five groups said correctly that the article was peer reviewed but two of the groups did not indicate that using the journal's Web site or Ulrich's Periodicals Directory was the way to be certain of this fact. In Part I, the students had to classify a particular article from the bibliography by type of source. Only two of the five groups correctly identified the paper as a review article. Retrieval of another paper via library resources in the bibliography was the task in Part J. Four of the five groups successfully found the article and were able to provide an accurate summary of the piece.

\section{First Semester: Culminating Class Project}

In addition to the three library instruction sessions in the early and middle parts of the semester, the librarians worked with the class on a five-day case study about the Galápagos Islands. ${ }^{32}$ The case study features events from the life of Kate, a graduate student new to the islands and seeking a research study for her doctoral work. The first two parts of the three-part activity challenge the students to understand the geological past and present of the islands, explore the development of its tropical flora and fauna, and define a host of evolutionary and ecological terms. The students worked in groups of four to five to tackle nineteen short-answer questions on these topics. The librarians aided the students' efforts by providing a small collection of relevant print reference works and showing them pertinent scholarly studies. The students were to cite their sources for each answer and, in the case of the use of open Web resources, provide information about why the source was credible.

Part III of the case study is entitled "The Tortoise and the Sea Cucumber." After many years of conflicting interests among constituent groups (scientists, tour guides, environmental groups, and sea cucumber fishermen), a sea cucumber crisis erupted in the Galápagos in the early to mid-1990s. The students worked in groups, researching positions for each of these constituent groups and, ultimately, through class discussion and negotiation, devising a compromise solution. The librarians taught the students about newspaper and magazine databases they would find fruitful in researching this topic. The groups' final case study reports illustrated research sophistication at a much higher level than the beginning of the semester. Just over three-quarters ( $76 \%$ ) of resources cited in the students' final case study derived from library sources. More than half (53\%) of their citations were to scholarly journal sources, and only 13 percent from nonacademic Web sites.

Student responses on the final course evaluations reflected their view that

\begin{tabular}{|l|}
\multicolumn{1}{|c|}{ FIGURE 1} \\
\multicolumn{1}{|c|}{ First Semester Course Evaluations: Most Significant Concepts Learned } \\
\hline $\begin{array}{l}\text { I learned how to use the library system and look up journal articles relevant to my } \\
\text { research. }\end{array}$ \\
\hline $\begin{array}{l}\text { To learn how to work with others effectively. Also, how to find articles through the } \\
\text { libraries system. }\end{array}$ \\
\hline I got experience reading scientific papers... \\
\hline Learning how to read scientific papers. \\
\hline This course taught me to critically analyze scientific research... \\
\hline
\end{tabular}




\begin{tabular}{|l|}
\multicolumn{1}{|c|}{ FIGURE 2} \\
\hline \multicolumn{1}{|c|}{ First Semester Course Evaluations: New Skills Acquired } \\
\hline $100 \%$ agree that in this course they made judgments about the value of information. \\
\hline $\begin{array}{l}84 \% \text { of students reported that they felt comfortable searching for primary scientific } \\
\text { literature (up } 35 \% \text { from precourse survey). }\end{array}$ \\
\hline $100 \%$ of students reported that they could locate related scholarly information. \\
\hline $\begin{array}{l}71 \% \text { of students reported that the library sessions helped them learn how to find and } \\
\text { retrieve electronic resources through the WSU Libraries. }\end{array}$ \\
\hline
\end{tabular}

information literacy was a central component of the course. When asked their judgment about the most significant course outcomes, 5 of the 14 students specifically mentioned understanding and using scientific research (see figure 1 for the responses). Most students also gained confidence in doing quality literature searches (see figure 2).

\section{Second Semester: Classroom Activities, Surveys, Assignments}

Assessment of student performance data and student feedback from the first semester guided several key changes in the course design and instructional approach, including library instruction, during the second semester. Changes included more modeling of target skills combined with increased hands-on practice and timely feedback. In addition, activities were more carefully scaffolded during the semester for improved skill development.

The experiences of the first semester led the instruction team to incorporate the expanded set of four library instruction sessions for the second semester, adjust the instructional approach, and add practice activities with feedback. The librarians focused on proactively teaching skills to search and evaluate scholarly articles, the two primary student problems from the first semester.

To address previous troubles that the students had using library resources to find articles, the librarians demonstrated the process using recent scientific articles, monitored students as they found several articles in class, gave feedback as needed, and also added a new short homework assignment requiring students to find an- other article. All 18 students successfully found an article. In the second semester, only 27 percent of students were unable to find the Moran homework article, an improvement from 60 percent in the first semester.

A new activity was added to the course to address the difficulties students had categorizing articles as primary or secondary. First, the students accessed a WSU Libraries' Web page (www.wsulibs. wsu.edu/usered/UH290.html) that provides a comprehensive overview of the differences between primary/secondary/ tertiary sources and review articles. After reading a specified subset of the learning modules, the full class debriefed about knowledge gained. Only two of the 20 students subsequently erred on the homework assignment by labeling primary sources as secondary, an improvement over the one-third who answered incorrectly the first semester. However, the teaching experience still needed enhancement as the two students faltered due to the misapprehension that inclusion of a literature review makes an article secondary (the same issue as the first semester).

Additionally, second semester homework assignments were changed to require use of CSE citation style. The instruction team wanted the students to have experience with the citation style most closely related to the disciplinary focus of the course. Although the librarians provided the URLs for several online CSE guides, the students struggled to produce accurate citations. First, the librarians realized they had neglected to explain that CSE has two formats; this fact created student confusion. Second, students had numerous 
issues with author name abbreviation and order, as well as article title capitalization. Third, students largely cited articles as if they were retrieved in print, when they should have had included electronic database information. Fourth, and most important, the librarians had not scaffolded the process, leaving out the steps of modeling the skill and then providing guided in-class practice with feedback.

During the second semester, the librarians added a library research skills self-assessment at the beginning of the first library instruction session, which provided additional information regarding students' prior experience and understanding of specific information literacy skills. (This tool was not used during the first semester because of lack of time.) The key results of this self-assessment are presented in figure 3.

Item 2 from figure 3 below points to why the students struggled to find scholarly articles through disciplinespecific article databases: nearly half had not previously used them. Item 3 illustrates that students largely did not know what a review article was. However, "primary source" was a vocabulary term in the list that 15 out of the 16 students believed they could confidently define. This matches the precourse survey results from both semesters, in which nearly all students correctly defined the term. Despite students' ability to define the term "primary source," and despite their past library instruction experiences, the overall assessment results illustrated that they needed to learn more about accessing and using library materials and services.

\section{Second Semester: Exams and Culminating Class Project}

The group take-home exam from the second semester (see Appendix B), though slightly different from the first semester exam, required students to demonstrate many of the same skills. Question 1, Part A (RE: scientist Randy Thornhill), challenged students to classify an article as primary or secondary. Given all of the prior in-class and out-of-class work on this topic earlier in the semester, it was gratifying that all five groups made the correct identification. Question 2, Parts A and $\mathrm{B}$, asked whether an article was peer reviewed and what evidence would allow the students to answer with "absolute certainty." All five groups said correctly that the article was peer reviewed (same as the first semester) and only one of the groups did not indicate that using the journal's Web site or Ulrich's Periodicals Directory was the way to be certain of this fact (which two groups had missed on the first-semester exam).

\begin{tabular}{|l|}
\multicolumn{1}{|c|}{ FIGURE 3} \\
\multicolumn{1}{|c|}{ Second Semester Pre-Library Instruction Student Self-Assessments } \\
\hline 1. 15 of the 16 students had had a prior library instruction session at WSU \\
\hline $\begin{array}{l}\text { 2. } 7 \text { of } 16 \text { had not used library resources beyond the catalog and our general } \\
\text { multidisciplinary database }\end{array}$ \\
\hline $\begin{array}{l}\text { 3. less than half of the students knew basic library research vocabulary such as serial, } \\
\text { manuscript, literature search, review article }\end{array}$ \\
\hline 4. only 3 of the 16 knew where to find library subject guides \\
\hline 5. none of the students knew the four ways to contact reference librarians \\
\hline 6. only $25 \%$ knew the basic difference between material in our catalog vs. article databases \\
\hline $\begin{array}{l}\text { 7. only } 1 \text { of } 16 \text { was familiar with WSU's central article interlibrary loan service: Article } \\
\text { Reach }\end{array}$ \\
\hline 8. only half knew how to use truncation in searching \\
\hline 9. only 6 of 16 could put three Library of Congress call numbers in shelf order \\
\hline
\end{tabular}


The latter parts of Question 1 focused on functionalities of Web of Knowledge (Science) and contextual use of criteria to evaluate scientific authority. Question 1, Part E, read as follows: "Search Steve Gangestad using the Web of Science 'Cited Reference Search' from 2000-2009 (scroll down to set search limits). How many of his publications have been cited? What are his two most cited publications?" With hindsight, the instruction team realized that wording of the exam question was problematic. First, there are actually two date limiters on the Cited Reference Search interface, and the instruction team neglected to specify which date limiter to use. One limits the search to articles that have received cites during the specified years, and the other only includes articles published during the specified years and receiving cites during those same years. Four of the five student groups opted to use the latter search functionality. Second, students were confused by the term "publication." The Cited Reference Search results list contains a column titled "Cited Work" that features the name of the journal for that article record. A subsequent click in a separate column is necessary to show the title of the article. In the exam question, the instruction team meant "publication" as individual article titles, but one group interpreted "publication" to mean the journal title.

To answer the question correctly, students had to grapple with the issue of the number of S. Gangestads in the Web of Science database, at which time there were six. Three of the five groups examined the Web of Science results and "our" Gangestad's Web site closely enough to discover his middle initial is " $\mathrm{W}$ " and is used in his professional work. The instruction team was impressed that 60 percent of the groups were able to successfully navigate name variations in the Web of Science even though this particular issue was not discussed in any library instruction session.

Overall, the instruction team learned a few important lessons from this experience. First, although the librarians had demonstrated topic searching in Web of Science and shown an example of how article records can be a launching point to prior works (from the bibliography) and future works (cited references), the librarians had modeled neither use of the cited reference search feature nor, consequently, its set of limiters. Also, the librarians could have shown the "Author Finder" feature, which would have helped as well. The exam question asked students to stretch their knowledge to a new area of Web of Science, but unfortunately the wording of the question lacked specificity. In the future, the librarians and instructor will collaborate on question creation more closely.

Question 1, Part F, read: "Find Randy Thornhill's webpage and scrutinize his curriculum vitae. By what criteria would you evaluate his scientific authority? THINK. Cite detailed evidence to support your evaluation-use specific criteria and evaluate his performance according to those criteria." Figure 4 shows the grading criteria that were used for this question.

The students did well with this question in terms of listing facets of his educational background and current employment. All five groups noted the quantity of his publications; three of the five outlined quality measures as well, including Journal Impact Factors and peer-reviewed status. The students largely missed the length of his career and exceptional consistency and high impact of his work as indicators of strong scientific authority. Overall, out of 30 points available for this question, the groups earned an average total of 26 . In the future, the instruction team will design a class activity on comparison of strong vs. weak researcher qualities as a measure of scientific authority.

The Galápagos case study was the culminating project both semesters. Changes made to the second semester's instruction included the following: students received a specific handout outlining ways to search for the Galápagos project in the newspaper and magazine databases, and 


\begin{tabular}{|l|}
\hline \\
SIGURE 4 \\
Second Semester Exam Question 1, Part F, Answer Key \\
\hline (1) Professional affiliation: U NM, Distinguished Professor \\
\hline (1) Education: advanced degrees (BS, MB, PhD) in zoology or related science \\
\hline (.5) Grad students (there are more than those listed) \\
\hline (4) Selected pubs (there are more than those listed): \\
(.5) length of career: began in 1980 (29 yrs ago) \\
(.25) consistency of scientific output: pubs every year \\
(1) academic discipline: human sexuality, evolution of sexuality, etc. \\
(1) primary source quality \& number: numerous v. high impact, peer reviewed \\
(1) review articles quality \& number: many v. high impact \\
(.25) other scientific pubs, quality \& number: numerous book chapters in best \\
university presses (Cambridge U, Oxford U, Harvard U) \\
\hline (.5) Research featured in prominent, respected popular outlets (Nat. Geog, BBC, \\
many national and international radio and TV programs) \\
\hline
\end{tabular}

the instructor highlighted the importance of the Galápagos research presentations. These were held in the Honors College Lounge (fancier venue than the regular classroom) and a set of teaching faculty members and librarians were invited to hear the presentations and ask questions. A student evaluation of the library instruction portion of the Galápagos experience was added, with mixed results. Although some students classified the library instruction as repetitive from prior sessions and library instruction sessions from other courses, many were very appreciative of guidance concerning the specific articles indexes for the Galápagos work.

\section{First and Second Semester Comparative Summary}

The second-semester syllabus maintained the increased number of library instruction sessions from the first semester. From the student comments above, it seems important that the librarians poll the class beforehand and then tailor instruction and activities to (1) ensure these sessions are not perceived as repetitive; (2) clearly articulate the sophisticated skill development required for completion of the culminating case study; and/or (3) design practice activities to accommodate a variety of skill levels. Citation style formatting
(CSE) and the features of Web of Science are two areas in which students could use more instruction (see above). The groups' final case study reports illustrated a high level of research sophistication. During the first semester, 76 percent of resources cited in the students' final case study derived from library sources, and 53 percent of their citations were to scholarly journal sources, with only 13 percent from Web sites. In the second semester, these values were 77 percent, 43 percent, and 23 percent, respectively.

In both semesters, when students assessed the course as a whole, they identified information literacy as a course focus, specifically noting the value of learning how to read and interpret the different sections of a science research article and how to find credible sources when doing research.

\section{Discussion/Conclusion}

It has been shown repeatedly that undergraduate students underestimate their need for advanced library instruction. Perhaps buoyed by their high school research experience, they enter college convinced that they know all they need and express confidence regarding their research skills. Testing this entry-level mindset against actual college-level research often shows that they lack the skills 
to locate scholarly resources. Honors students in UH 290 fit this pattern. Early assessment of students' collaborative online work revealed that 40 percent of the groups could not locate scholarly journals using library resources. Students were searching with Google because they did not know how to locate resources through the WSU libraries.

In this course, frequent assessment of student skills revealed gaps, misperceptions, and bottlenecks that limited success in target information literacy outcomes. Timely assessment results gave the instructional team information that they used to make instructional changes. Realizing that the students had not learned core information literacy techniques, the instructional team engaged in midcourse corrections to the syllabus and learning activities, resulting in significant improvements in student learning.

Multiple assessment techniques were integrated into the course design. Performance-based homework assignments and exam questions required students to apply and explain information literacy skills, providing direct measurements. Pre- and post-tests allowed the instructor and librarians to measure changes in student comprehension. Student surveys were used to gauge students' self-perceptions of their knowledge and skills. Following online threaded group discussions allowed the instructor and librarians to immediately see misperceptions and bottlenecks and to address them via timely feedback and adjustments to the syllabus, teaching approach, and learning activities.

In the final research project, students demonstrated their increased understanding of the types of material suitable for academic papers and their ability to locate the material. The final works-cited lists for each semester contained, respectively, 53 percent $/ 43$ percent citations from scholarly sources and 76 percent/77 percent from library sources. The Web sites used $(13 \% / 23 \%)$ were authoritative and reliable. The remaining sources from newspapers and magazines were appropriate to the opinion analysis the Galápagos project entailed. A total of 29 percent of the bibliographic entries were noted as excellent by the professor. This was a great improvement from roughly half the students not being able to find articles in the library and the initial inability of many students to judge quality and authority of resources at the beginning of each semester.

It was gratifying that, according to postcourse surveys from both semesters, students strongly agreed/agreed that they are now comfortable conducting a literature search for primary scientific articles and that they have enhanced their ability to critically analyze a scientific paper. The authors feel that this final result was a reflection of our truly integrative and collaborative instruction.

The primary course instructor, librarians, and assessment expert were involved in all facets of the course from the outset, with librarians contributing to course design. Library instruction sessions were integral to the course: librarians provided instruction, in-house practice with feedback, and selected assignments. Library homework assignments were integral to course goals and content, not just "addons" for the purpose of teaching library skills. This close collaboration enabled the instruction team to make effective midcourse corrections, addressing deficiencies in students' understanding and performance. Over the two semesters, the instruction team implemented scaffolded instruction, and the assessment specialist helped ensure that multiple measures were complementary and that changes were assessed.

\section{Advice to Teaching Librarians}

- Don't be afraid to ask to become more involved in the course on which you are collaborating. You will be more effective if your library sessions are integral to the course rather than merely appended.

- Look over assignments and offer 
suggestions. By including information literacy elements in many assignments, the students will start to equate good library research skills with good practice in the science they are studying. This also offers more opportunities to assess their working skills.

- Don't be apprehensive about suggesting information literacy questions on exams that call on students to apply their research skills to the discipline. These types of questions illustrate students' authentic use of research techniques.

- Major course projects offer a perfect opportunity to ensure that the students can effectively incorporate library research with their science while impressing on them the critical role of library research in the scientific process.

- Assessment is not just a way to analyze how successful you were at teaching library skills. It is a method for evaluating student performance and refining your approaches.

- Assessment techniques should be varied: for example, pre- and postcourse surveys, graded and ungraded class assignments, and exams (timed, take-home, individual, group).

- Don't become disheartened. Next semester offers the chance to do it better! 


\section{Appendix A: Question Four from First Semester Take-Home Exam}

4. Go to the following link:http://www.reuters.com/article/email/idUSN0742189220080508 and read about "sexy orchids." Then, locate the original publication (via WSU Libraries) and answer the following questions:

a. Is this a peer-reviewed publication? What evidence can you provide that allows you to answer this question with absolute certainty? (Hint: Remember our trip to Owen Science Library.)

b. From the Introduction: What two null hypotheses do the authors test here? (Note: I am not referring to their meta-analyses, and your answer must be in the form of null hypothesis statements.)

c. How many blobs of sperm ejaculate were brought from the field to the lab for analysis?

d. How many total L. excelsa did the researchers use to generate the data presented in Fig. 2?

e. Where did the researchers obtain the data that they used to conduct their first meta-analysis?

f. Figure 3 states, "Orchid species causing ejaculation...have higher pollination success than orchids stimulating less extreme sexual behavior..." Is this statement supported by statistically significant data? On what do you base your opinion?

g. In the Discussion section, the researchers state, "Pollinators of Cryptostylis... do learn to avoid sexually deceptive orchids." Did they demonstrate this in their study? On what specifically do you base your opinion?

h. In their Abstract the researchers state, “...female insects deprived of matings by orchid deception could still produce male offspring, which may even enhance orchid pollination." What evidence do they present in support of that hypothesis?

i. In the Literature Cited section, what type of source is the publication by Wedell et al. (2002)?

j. The authors cite a publication by Schiestl et al. (1999). Retrieve this via WSU Libraries. In your own words (50 or less!), what did Schiestl et al. demonstrate? 


\section{Appendix B: Question One from Second Semester Take-Home Exam}

Information Literacy, re: Human evolutionary biology. Retrieve these articles via WSU Libraries and answer the questions that follow.

- $\quad$ Thornhill and Gangestad. 1996. Trends in Ecology E Evolution 11(2):98-101.

a) Is this a primary or secondary article?

b) What is this journal's impact factor?

c) from p. 98: What do studies in evolutionary psychology indicate about the sexual psyches of heterosexual men vs women? (Use specific examples and state in your own words.) Why does theory predict the evolution of these behavioral differences?

d) from p. 100: In plain English, what is fluctuating asymmetry (FA)? Name 2 things that cause it to increase, 4 different things that it predicts, and explain why physical attractiveness may be of evolutionary significance.

e) Search Steve Gangestad using the Web of Science "Cited Reference Search" from 2000-2009 (scroll down to set search limits). How many of his publications have been cited? What are his two most cited publications?

f) Find Randy Thornhill's Web page and scrutinize his curriculum vitae. By what criteria would you evaluate his scientific authority? THINK. Cite detailed evidence to support your evaluation-use specific criteria and evaluate his performance according to those criteria.

- $\quad$ Koehler et al. 2002. Animal Behavior 64:233-238. [Note: you only need p. 233]

a) Is the journal peer reviewed? How do you know for certain?

b) State the null hypothesis for this study.

c) Did these researchers accept or reject the null?

d) What is this journal's impact factor?

- Kuukasjärvi et al. 2004. Behav. Ecol. 15(4):579-584.

a) What is concealed ovulation?

b) Do dogs have this? What's your evidence?

c) What is the reason the study includes women who were on oral contraceptives?

d) What is the reason for including women as raters?

e) In the Methods section, "Odor rating sessions," why do the authors state that the supervising researchers did not know who had worn the T-shirts?

f) Which of the regressions (a through d) depicted in Figure 1 is/are significant? How do you know this?

g) What is this journal's impact factor?

- Miller et al. 2007. Evolution and Human Behavior 28:375-381.

a) What is the impact factor for this journal?

b) from Introduction: What are the two competing views regarding human female estrus? Summarize the findings of the four "real-world" situation studies cited by Miller et al. What critiques do the current authors note regarding these studies?

c) from Introduction: Why do Miller et al. argue that estrus attractiveness effects may be stronger in their study than in other kinds of psychology research studies?

d) from Results, 4.3: In your own words, what two planned contrasts did the researchers make (Fig. 2), and which were statistically significant?

c) from Discussion: According to the authors, what do their findings suggest about the concealed ovulation model?

d) For fun: The authors accept a 2008 IgNobel award for their research (see lower video @ time=1:18:00): http://improbable.com/ig/2008/webcast/ 


\section{Notes}

1. Presidents Teaching Academy, Washington State University, available online at http://vpue. wsu.edu/overview/sixgoals/ [accessed 22 June 2010].

2. Abigail Loomis and Patricia Herrling, "Course-Integrated Honors Instruction: Pros and Cons," in "What Is Good Instruction Now?" Ann Arbor, MI: Pierian Press, 1993: 84.

3. Megan Oakleaf, "Dangers and Opportunities: A Conceptual Map of Information Literacy Assessment Approaches," portal: Libraries and the Academy 8, no.3 (2008): 233-34.

4. Loomis and Herrling, "Course-Integrated Honors Instruction," 84.

5. Debra Cox Rollins, Jessica Hutchings, Melissa Ursula, Dawn Goldsmith, and Anthony J. Fonseca, "Are We There Yet? The Difficult Road to Re-Create Information Literacy," portal: Libraries and the Academy 9, no. 4 (2009): 454, 464.

6. Ibid., $456-57$.

7. Catherine Frasier Riehle, "Partnering and Programming for Undergraduate Honors Students," Reference Services Review 36, no. 1 (2008): 49; Renee B. Bush and Margaret R. Wells, "Bibliographic Instruction for Honors Students: The University at Buffalo Experience," Research Strategies 8, no. 3 (1990): 137.

8. Oakleaf, "Dangers and Opportunities," 234.

9. Rollins et al., "Are We There Yet?" 463.

10. American Association for Higher Education and Accreditation (AAHEA), "9 Principles of Good Practice for Assessing Student Learning" (1996), available online at http://assessment. uncg.edu/9Principles.pdf [accessed 22 June 2010].

11. Ibid.

12. Oakleaf, "Dangers and Opportunities," 237.

13. Ibid., 238.

14. Ibid., 240.

15. Loanne L. Snavely and Carol A. Wright, "Research Portfolio Use in Undergraduate Honors Education: Assessment Tool and Model for Future Work," The Journal of Academic Librarianship 29, no. 5 (2003): 298-303.

16. Elizabeth W. Kraemer, "Developing Information Literacy Instruction for Honors Students at Oakland University: An Information Consulting Approach," College \& Undergraduate Libraries 14, no. 3 (2007): 64.

17. Loomis and Herrling, "Course-Integrated Honors Instruction," 83.

18. Ibid., 85.

19. Ibid., 85,89 .

20. Ibid., 85,86 .

21. Ibid., 87.

22. Ibid., $86,87$.

23. Kraemer, "Developing Information Literacy Instruction," 64, 65; Snavely and Wright, "Research Portfolio Use," 299.

24. Kraemer, "Developing Information Literacy Instruction," 66, 67.

25. Kraemer, "Developing Information Literacy Instruction," 70.

26. Ignacio J. Ferrer-Vincent and Christy A. Carello, "Embedded Library Instruction in a FirstYear Biology Laboratory Course," Science E Technology Libraries 28, no. 4 (2008): 326.

27. Ibid., 329-31.

28. Ibid., 335.

29. Ibid., 335, 337.

30. Christopher M. Gillen, Reading Primary Literature: A Practical Guide to Evaluating Research Articles in Biology (San Francisco: Pearson Education, Inc., 2007, 44 pp.)

31. Amy L. Moran, "Egg Size Evolution in Tropical American Arcid Bivalves: The Comparative Method and the Fossil Record," Evolution 58, no. 12: 2718-33.

32. Nancy A. Schiller and Clyde Freeman Herreid, "The Galápagos," available online at http:// ublib.buffalo.edu/libraries/projects/cases/galapagos1.html [accessed 22 June 2010]. 